\title{
The origin of the inferior epigastric artery in relation to the inguinal ligament in various periods of human life
}

\author{
Mariusz Klepacki ${ }^{1}$, Monika Cendrowska-Pinkosz ${ }^{1}$, \\ Wojciech Dworzanski ${ }^{1}$, Franciszek Burdan ${ }^{1,2}$
}

\author{
${ }^{1}$ Department of Human Anatomy, Medical University of Lublin, 4 Jaczewskiego, 20-090 Lublin, Poland \\ ${ }^{2}$ St. John's Cancer Center; Lublin, Poland
}

\begin{tabular}{l}
\hline ARTICLE INFO \\
\hline Received 30 June 2014 \\
Accepted 20 October 2014 \\
\hline
\end{tabular}

\section{Keywords:}

inferior epigastric artery,

external iliac artery,

pelvis,

inguinal ligament.

\begin{abstract}
The aim of the study was to evaluate the origin of the inferior epigastric artery, in relation to the inguinal ligament, in various stages of human life. The study was conducted on randomly selected 220 non-fixed cadavers, including 110 males and 110 females, from the age of the 7th month of prenatal life, to 82 years. In all examined bodies, the inferior epigastric artery originated mostly from the external iliac, or less commonly, from the femoral artery. Three types of origin were observed: above, at the level or below the ligament. In males, the lowest incidence of typical anatomical origin, over the ligament, was observed in the group aged 60-69 years. Herein, the artery departed usually on the level of the ligament. The highest incidence of typical anatomical origin was found during the prenatal period and among children. Similar data, but with higher asymmetry, was revealed among females. The lowest incidence of typical origin was seen on the left side in the group aged 60-69. Less commonly, the artery originated at the level or occasionally below the ligament. In conclusion, the origin of the inferior epigastric artery differs throughout prenatal and postnatal life, in both sexes. However, it is usually located above the inguinal ligament.
\end{abstract}

\section{INTRODUCTION}

The inferior epigastric artery (IEA) departs usually from the anterior aspect of the external iliac artery above the inguinal ligament. It then runs superiorly, back to the interfoveolar ligament, medially to the deep inguinal ring. On this level, the artery crosses the ducts deferens $\left({ }^{1}\right)$ or round ligament of the uterus ( $($ ) that is supplied by its own branches. Superiorly, it is located on the posterior surface of the transversus abdominis aponeurosis, where the transversalis fascia elevates and the peritoneum forms the lateral umbilical fold. Finally, it reaches the posterior surface and the rectus abdominis muscle, and, $5-6 \mathrm{~cm}$ above the umbilical ring, anastomoses with the superior epigastric artery. Over the arcuate line, the artery is covered by the posterior layer of the rectus sheath, and at its end, it enters the belly muscle. Its terminal part supplies the anterior wall of the abdominal cavity by way of its muscular and cutaneous branches [1-3,6,20,22].

Corresponding author

e-mail: mppinkosz@poczta.onet.pl
The topography of the artery is especially important for surgeons, since its obdurate branch (which usually arises from the pubic branch) anastomoses with the epigastric branch from the obturator artery $[2,13]$. Such an arterial arch, the so-called corona mortis [crown of dead], is located on the posterior aspect of the deep femoral ring, and could be accidentally injured during various surgical procedures, e.g, femoral hernia repair [13]. Moreover, the topography of IEA determines the safe zone of entry of the anterior abdominal wall during laparoscopic procedures $[4,11,15,18]$.

The aim of the study was to evaluate the origin of the interior epigastric artery in relation to the inguinal ligament, in various pre- and postnatal periods of human life, in both genders.

\section{MATERIALS AND METHODS}

The study was conducted on 220 Caucasian human bodies of both sexes, aged from the 7th month of the prenatal period, to 82 years, during the routine post-mortem examination performed for various medical or legal reasons. The 
study was performed according to the Polish law, on human bodies after a routine medical or coroner autopsy at the Pathomorphology and Forensic Medicine Departments of the Medical University of Lublin, as well as at the Forensic Medicine Department of the Warsaw Medical University in the years between 1987-1999.

The causes of death of the study population was not related to any vascular, pelvic and anterior abdominal wall abnormalities. The analyzed population (110 males, 110 females) was placed into 19 groups according to their age (Table 1-2). For the study, the external iliac artery and their branches underwent direct preparation. Each time, the origin of the inferior epigastric artery was compared with the position of the inguinal ligament.

\section{RESULTS}

In all examined bodies, the inferior epigastric artery originated mostly from the external iliac or less commonly from the femoral artery. Three types of origin of the artery were observed: above, at the level and below the ligament. The distance to the inguinal ligament was up to 10 and $5 \mathrm{~mm}$ above and below the structure, respectively.

In males, the lowest incidence of typical anatomical origin, over the ligament, was observed in the group aged 60-69 years, and, in this group, the artery departed usually on the level of the ligament (Table 1). The highest incidence of typical anatomical origin was found during the prenatal period and among children. Similar data, but with higher asymmetry was revealed among females (Table 2). The lowest incidence of typical origin was seen on the left in the group aged 60-69. Less commonly, the artery originated at the level or occasionally below the ligament.

\section{DISCUSSION}

The current study indicates a great variation with regard to the inferior epigastric artery in relation to the inguinal ligament. According to the classical description, this artery usually arises from the anterior aspect of the external iliac artery, and runs above the ligament [1-7,10-20,22]. As it was pointed out above, such an origin is the usually assumed during laparoscopy $[4,11,13,18]$. However, departure from the femoral artery, whether below the inguinal ligament or from the external iliac artery by way of a common trunk with the obturator artery, or as a principal branch of the obturator artery, has also reported $[2,4,8,16]$. What is more, occasionally, the inferior epigastric artery has been seen to have a common trunk with the deep femoral artery and the medial circumflex artery of the thigh or with both vessels $[1,2]$. However, none of such rare origins were observed among the evaluated population.

According to Luzsa [10] and Kopsch [6], the origin of this artery is normally $5 \mathrm{~mm}$ above the inguinal ligament, but Poirer [12] and Worobiew [22] stress that this is actually 8-10 and 5-10 mm, respectively. What is more, Adachi [1] describes the beginning of the artery to be immediately above the upper margin of the inguinal ligament, and notes that an extremely high origin (20-30 $\mathrm{mm}$ above), while appearing very rarely, was also described by Testut [20] and Bochenek [2]. However, in our study, the artery was to usually depart slightly above the ligament - up to $10 \mathrm{~mm}$.

Table 1. The origin of the inferior epigastric artery in relation to the inguinal ligament in males

\begin{tabular}{|c|c|c|c|c|c|c|c|c|c|c|c|c|c|}
\hline \multirow{3}{*}{ age } & \multirow{3}{*}{$n$} & \multicolumn{6}{|c|}{ right } & \multicolumn{6}{|c|}{ left } \\
\hline & & \multicolumn{2}{|c|}{ A } & \multicolumn{2}{|c|}{$L$} & \multicolumn{2}{|c|}{$B$} & \multicolumn{2}{|c|}{ A } & \multicolumn{2}{|c|}{$L$} & \multicolumn{2}{|c|}{$B$} \\
\hline & & $n$ & $\%$ & $n$ & $\%$ & $\mathrm{n}$ & $\%$ & $\mathrm{~N}$ & $\%$ & $\mathrm{n}$ & $\%$ & $n$ & $\%$ \\
\hline $7 \mathrm{gm}$ & 4 & 3 & 75 & 1 & 25 & - & - & 3 & 75 & - & - & 1 & 25 \\
\hline $8 \mathrm{gm}$ & 3 & 1 & 33.33 & 2 & 66.67 & - & - & 3 & 100 & - & - & - & - \\
\hline $9 \mathrm{gm}$ & 3 & 3 & 100 & - & - & - & - & 3 & 100 & - & - & - & - \\
\hline newborn & 10 & 9 & 90 & 1 & 10 & - & - & 10 & 100 & - & - & - & - \\
\hline $1-3 \mathrm{~m}$ & 2 & 1 & 50 & 1 & 50 & - & - & 2 & 100 & - & - & - & - \\
\hline $4-6 \mathrm{~m}$ & 5 & 3 & 60 & 2 & 40 & - & - & 3 & 60 & 1 & 20 & 1 & $2 C$ \\
\hline 7-11 m & 3 & 1 & 33.33 & - & - & 2 & 66.67 & 3 & 100 & - & - & - & - \\
\hline $1-3 y$ & 4 & 3 & 75 & - & - & 1 & 25 & 3 & 75 & 1 & 25 & - & - \\
\hline $4-6 y$ & 3 & 3 & 100 & - & - & - & - & 1 & 33.33 & 2 & 66.67 & - & - \\
\hline $7-9 y$ & 3 & 3 & 100 & - & - & - & - & 3 & 100 & - & - & - & - \\
\hline $10-12$ y & 2 & 2 & 100 & - & - & - & - & 2 & 100 & - & - & - & - \\
\hline $13-16$ y & 3 & 2 & 66.67 & - & - & 1 & 33.33 & 2 & 66.67 & 1 & 33.33 & - & - \\
\hline $17-19 y$ & 5 & 5 & 100 & - & - & - & - & 2 & 40 & 3 & 60 & - & - \\
\hline $20-29 y$ & 10 & 3 & 30 & 2 & 20 & 5 & 50 & 5 & 50 & 5 & 50 & - & - \\
\hline $30-39$ y & 10 & 6 & 60 & 4 & 40 & - & - & 4 & 40 & 5 & 50 & 1 & 10 \\
\hline $40-49$ y & 10 & 7 & 70 & 3 & 30 & - & - & 6 & 60 & 2 & 20 & 2 & 20 \\
\hline $50-59$ y & 10 & 8 & 80 & - & - & 2 & 20 & 4 & 40 & 4 & 40 & 2 & 20 \\
\hline $60-69$ y & 10 & 1 & 10 & 9 & 90 & - & - & 2 & 20 & 3 & 30 & 5 & 50 \\
\hline$\geq 70 \mathrm{y}$ & 10 & 4 & 40 & 3 & 30 & 3 & 30 & 6 & 60 & 3 & 30 & 1 & 10 \\
\hline
\end{tabular}

(gm - gestational month, $\mathrm{m}$ - postnatal month, $\mathrm{y}$ - postnatal year) A - above the ligament; $\mathrm{L}$ - at the level of the ligament; $\mathrm{B}$ - below the ligament 
Table 2. The origin of the inferior epigastric artery in relation to the inguinal ligament in females

\begin{tabular}{|c|c|c|c|c|c|c|c|c|c|c|c|c|c|}
\hline \multirow{3}{*}{ age } & \multirow{3}{*}{$n$} & \multicolumn{6}{|c|}{ right } & \multicolumn{6}{|c|}{ left } \\
\hline & & \multicolumn{2}{|c|}{ A } & \multicolumn{2}{|c|}{ L } & \multicolumn{2}{|c|}{ B } & \multicolumn{2}{|c|}{ A } & \multicolumn{2}{|c|}{ L } & \multicolumn{2}{|c|}{ B } \\
\hline & & $n$ & $\%$ & $n$ & $\%$ & $n$ & $\%$ & $\mathrm{~N}$ & $\%$ & $\mathrm{n}$ & $\%$ & $n$ & $\%$ \\
\hline $7 \mathrm{gm}$ & 2 & 2 & 100 & - & - & - & - & 2 & 100 & - & - & - & - \\
\hline $8 \mathrm{gm}$ & 6 & 6 & 100 & - & - & - & - & 5 & 83.33 & - & - & 1 & 16.67 \\
\hline $9 \mathrm{gm}$ & 2 & 2 & 100 & - & - & - & - & 1 & 50 & 1 & 50 & - & - \\
\hline newborn & 10 & 8 & 80 & 1 & 10 & 1 & 10 & 9 & 90 & 1 & 10 & - & - \\
\hline $1-3 \mathrm{~m}$ & 4 & 3 & 75 & - & - & 1 & 25 & 3 & 75 & 1 & 25 & - & - \\
\hline $4-6 m$ & 3 & 1 & 33.33 & 2 & 66.67 & - & - & 3 & 100 & - & - & - & - \\
\hline 7-11 m & 3 & 3 & 100 & - & - & - & - & 2 & 66.67 & 1 & 33.33 & - & - \\
\hline $1-3 y$ & 6 & 6 & 100 & - & - & - & - & 5 & 83.33 & - & - & 1 & 16.67 \\
\hline $4-6 y$ & 2 & 2 & 100 & - & - & - & - & - & - & 2 & 100 & - & - \\
\hline $7-9 y$ & 2 & 2 & 100 & - & - & - & - & 2 & 100 & - & - & - & - \\
\hline $10-12$ y & 3 & 1 & 33.33 & 2 & 66.67 & - & - & 2 & 66.67 & 1 & 33.33 & - & - \\
\hline $13-16 y$ & 1 & 1 & 100 & - & - & - & - & 1 & 100 & - & - & - & - \\
\hline $17-19 y$ & 6 & 6 & 100 & - & - & - & - & 4 & 66.67 & 2 & 33.33 & - & - \\
\hline $20-29$ y & 10 & 6 & 60 & 2 & 20 & 2 & 20 & 6 & 60 & 2 & 20 & 2 & 20 \\
\hline $30-39$ y & 10 & 4 & 40 & 6 & 60 & - & - & 7 & 70 & - & - & 3 & 30 \\
\hline $40-49$ y & 10 & 6 & 60 & 1 & 10 & 3 & 30 & 3 & 30 & 7 & 70 & - & - \\
\hline $50-59$ y & 10 & 3 & 30 & 4 & 40 & 3 & 30 & 8 & 80 & - & - & 2 & 20 \\
\hline $60-69$ y & 10 & 7 & 70 & 2 & 20 & 1 & 10 & 2 & 20 & 3 & 30 & 5 & 50 \\
\hline$\geq 70 y$ & 10 & 6 & 60 & - & - & 4 & 40 & 7 & 70 & 3 & 30 & - & - \\
\hline
\end{tabular}

(gm - gestational month, $\mathrm{m}$ - postnatal month, $\mathrm{y}$ - postnatal year) A - above the ligament; L - at the level of the ligament; B - below the ligament

Similar to the current data, Bochenek [2] described the origin of the inferior epigastric artery to be above the level of the inguinal ligament in $57 \%$ of his sample population, at the level of the ligament in $28 \%$ of this population and below this in $15 \%$ of all cases he examined. Furthermore, similar results were also presented by Adachi [1]. In the group of 111 bodies investigated in our study, 63 vessels originated above (41 males and 22 females), 31 at the level (27 males and 4 females) and 17 below the ligament (16 males and 1 female). It has to be mentioned that the lower origin (below the ligament), changes the topography of the artery, which usually runs along the femoral vein and enters the abdominal cavity posteriorly to the inguinal ligament. Unlike our study, in which IEA originated slightly below the ligament (usually up to $5 \mathrm{~mm}$ ), Ercakmak [5] describes a very low departure $-13 \mathrm{~mm}$ below the ligament.

It is worth mentioning that in the examined population, similar data was revealed for the deep circumflex iliac artery - which is another typical branch of the external iliac artery [7]. In males aged up to 20-years-old, the artery was found to arise mostly above the ligament (48\%), whereas in individuals over 20 -years-old, this came about below it (47\%). In females younger than 20-years-old, the artery departed mostly at the level (54\%), while in older females, this occurred below the inguinal ligament (57\%).

In conclusion, the origin of the inferior epigastric artery differs throughout prenatal and postnatal life in both sexes. However, in adults, it is usually located above the inguinal ligament. We suggest that the obtained results may be related to the relative ascending of the arteries being secondary to the much faster growth (elongation) of the skeleton and muscle throughout the prenatal and postnatal period. Verifying this must be done through another study, as the main limitation of the current work is the lack of any prospective data and the low number of evaluated cases, even if the current work utilized probably the largest population among the available literature.

\section{REFERENCES}

1. Adachi B. (editor): Das Arteriensystem der Japaner. Kaiserlich Japanischen Universität, Kioto1928.

2. Bochenek A., Reicher M. (editor): Anatomia człowieka. PZWL, Warszawa 2007.

3. Buchel E.W., Dalke K.R., Hayakawa T.E.: Rethinking the superficial inferior epigastric artery flap in breast reconstruction: video demonstration of a rapid, reliable harvest technique. Can J Plast Surg, 21,99-100, 2013.

4. Ebstein J., Arora A., Ellis H.: Surface anatomy of the inferior epigastric artery in relation to laparoscopic injury. Clin Anat, 17,400408, 2004.

5. Ercakmak B. et al: A combined anatomical variation of inferior epigastric vessels. Folia Morph, 71,267-268, 2012.

6. Kopsch F.R. (editor):Rauber-Kopsch Lehrbuch u. Atlas der Anatomie des Menschen. VEB Georg Thieme, Leipzig 1955.

7. Klepacki M. et al.: The origin of the deep circum flexiliac artery in relation to the inguinal ligament in various period of human life. Curr Issues Pharm Med Sci, 26,313-316, 2013.

8. Levent S., Muzaffer S.: Multiple vessel variations in the retropubic region Folia Morph, 61,43-45, 2002.

9. Levent $S$. et al.: Anastomotic vessels in the retropubic region: corona mortis. Folia Morph, 62,179-182, 2003.

10. Luzsa G. (editor) X-ray anatomy of the vascular system. Akademiai Kiado, Budapest 1974.

11. Manvikar P.R. et al.: Study of the course of inferior epigastric artery, with reference to laparoscopic portal. J Minim Access Surg, 9,154158, 2013. 
12. Poirier P. (editor) :Traite d'anatomie humaine. Masson et Cie, Paris 1986.

13. Pungpapong S.U., Thum-Umnauyauk S.: Incidence of corona mortis; preperitoneal anatomy for laparoscopic hernia repair. J Med Assoc Tai, 88,51-53, 2005.

14. chroeter P. (editor): Zarys anatomii topograficznej. Wydawnictwo Trzaski Evert i Michalskiego, Warszawa 1922.

15. Seo M.H. Et al: Influence of vascular twisting on the supermicroanastomosis of superficial inferior epigastric artery. J Craniofac Surg, 24,1772-1780, 2013

16. Shanhan D., Jordan R.K .: Rare origin of inferior epigastric artery from anomalous medial circumflex femoral artery. J Anat, 191,611613, 1997.

17. Sieglbauer F. (editor):Lehrbuch der normalen Anatomie des Menschen. Urban \& Schwarzenberg, Wien 1963.
18. Sriprasad S. et al: Positional anatomy of vessels that may be damaged at laparoscopy: New access criteria based on CT and ultrasound to avoid vascular injury. J Endourol, 20,498-503, 2006.

19. Steinberg C.R., Archer M., Steinberg I.: Measurement of the abdominal aorta after intravenous aortography in health and arteriosclerotic peripheral vascular disease. Am J Roentgenol, 95,703708, 1965.

20. Testut L., Latarjet A.( editor): Traite d'anatomie humaine. Doin\&Cie, Paris 1948.

21. Wormald J.C., Wade R.G., Figus A.: The increased risk of adverse outcomes in bilateral deep inferior epigastric artery perforator flap breast reconstruction compared to unilateral reconstruction: A systematic review and meta-analysis. J Plast Reconstr Aesthet Surg, 67,143-156,2014.

22. Worobiew W.P., Sinielnikow R.D. (editor): Atłas anatomii czełowieka. Narkomzdraw SSSR Medgiz, Moskwa 1948. 